\title{
FIVE-LEVEL DTC WITH 12 SECTORS OF INDUCTION MOTOR DRIVE USING NEURAL NETWORKS CONTROLLER FOR LOW TORQUE RIPPLE
}

\author{
Habib BENBOUHENNI \\ Ecole Nationale Polytechnique d'Oran, Algeria \\ Tel.+2136632956329, E-mail: habib_benbouhenni@yahoo.com
}

\begin{abstract}
This paper presents an improved five-level DTC with 12 sectors of induction motor based on artificial neural networks controller. This neural controller was used to replace on the conventional comparator hysteresis of torque in order to reduce torque ripple, flux and stator current. The validity of the proposed control scheme is verified by simulation tests of an induction motor drive system. The stator current and stator flux, torque is determined and compared to the above techniques using Matlab/Simulink environment.
\end{abstract}

Keywords: Five-level DTC, Induction motor, 12 sectors, Neural controller, Comparator hysteresis, Torque ripple.

\section{INTRODUCTION}

In many variable speeds drive applications (e.g. traction drives for electric vehicles), torque control is required or desired, but precise, closed-loop control of speed is not necessary. Torque control provides greatly improved transient response, avoidance of nuisance overcurrent trips, and elimination of load dependent controller parameters [1]. The direct torque control (DTC) of the induction machine was introduced in 1986 by I. Takahashi and M. Depenbrock. The DTC is based on the orientation of the stator flux vector by direct action on the status of the converter switches [2].

The main advantages of DTC are the simple control scheme, a very good torque dynamic response, as well as the fact that it does not need the rotor speed or position to realize the torque and flux control, moreover DTC is not sensitive to parameters variations (except stator resistor) [3]. However, the high torque ripple problem allied with the basic DTC system can be reduced by efficiently increasing the output resolution of the inverter. Many methods have already been introduced to address this problem such as zero state modulation, space vector modulation (SVM) and the application of multilevel inverter [4].

Over the past years, the utilization of multilevel inverter topology in the DTC system has gained popularity for the medium and high voltage applications. Typicaly, there are three types of multilevel inverters topologies. Those types are the neutral point clamped (NPC), flying capacitor (FC) and cascade H-bridge multilevel inverters (CHMI) [5]. In the other hand, multilevel inverters have the advantages of over coming voltage limit capability of semiconductor switches, and improving, 2 harmonic profiles of output waveforms. The output voltage waveform approaches a sine wave, thus having practically no common-mode voltage and no voltage surge to the motor windings. Furthermore, the reduction in $\mathrm{dv} / \mathrm{dt}$ can prevent motor windings and bearings from failure [6].

In general the NPC topology has been constructed by higher number of power switches so thus additional control scheme required. DC link neutral point clamping is need for maintaining balanced voltage. High number of five level NPC inverter fed with high performance IM drives which is requires decoupled torque and flux control [7]. In this paper proposes a novel scheme of DTC to improve the drive performance. Neural direct torque control is used to improve dynamic response performance and decrease the stator flux and torque ripples.

\section{MODEL OF INDUCTION MOTOR}

The mathematical model of induction motor is developed based on state variable approach referred to stationary reference frame $(\alpha, \beta)$ using the following equations [8]. The mathematical model of IM is given by $[9,10]$ :

$$
\begin{aligned}
& X=A \cdot X+B . U \\
& Y=C . X
\end{aligned}
$$

Where $\mathrm{A}, \mathrm{B}$ and $\mathrm{C}$ are the evolution, the control and the observation matrices respectively.

$$
\begin{aligned}
& X=\left[\begin{array}{c}
i_{s} \alpha \\
i_{s} \beta \\
\Phi_{s \alpha} \\
\Phi_{s} \beta
\end{array}\right] ; U=\left[\begin{array}{c}
V_{s} \alpha \\
V_{s}
\end{array}\right] \\
& A=\left[\begin{array}{cccc}
\lambda & 0 & \frac{1-\sigma}{\sigma . M . T r} & \frac{w(1-\sigma)}{\sigma . M} \\
0 & \lambda & -\frac{1-\sigma}{\sigma . M} w & \frac{w(1-\sigma)}{\sigma \cdot M . T r} \\
\frac{M}{T r} & 0 & \frac{-1}{T r} & -w \\
0 & \frac{M}{T r} & w & \frac{-1}{T r}
\end{array}\right] \\
& B=\left[\begin{array}{cc}
\frac{1}{\sigma \cdot L_{S}} & \frac{1}{\sigma \cdot L_{S}} \\
0 & 0 \\
1 & 1
\end{array}\right] ; C=\left[\begin{array}{cccc}
1 & 0 & 0 & 0 \\
0 & 1 & 0 & 0
\end{array}\right]
\end{aligned}
$$

With, $\omega$ Rotor speed and the machine's parameters: $\mathrm{Rs}, \mathrm{Rr}$ are respectively the stator and the rotor resistance, 
M, Ls, Lr are respectively the mutual, the stator and the rotor cyclic inductances, $\mathrm{p}$ denotes the number of pole pairs, with:

$$
T_{r}=\frac{L_{r}}{R_{r}} ; \sigma=1-\frac{M^{2}}{L_{S} \cdot L_{r}} ; \lambda=-\left[\frac{1-\sigma}{\sigma . T_{r}}+\frac{1}{\sigma . T S}\right] ; T_{S}=\frac{L_{S}}{R_{S}}
$$

The mechanical equation is the following:

$$
J \dot{\Omega}=T e-\operatorname{Tr}-\operatorname{fr} \Omega
$$

\section{STRUCTURE OF FIVE-LEVEL INVERTER}

Multilevel inverter structures have been developed to overcome shortcomings in solid-state switching device ratings so they can be applied to higher voltage systems [11]. In 1980, early interest in multilevel power conversion technology was triggered by the work of Nabae, who introduced the neutral-point-clamped (NPC) inverter topology [12]. The main concept of this inverter is to use diodes to limit the power devices voltage stress [13]. The topology that have been used in this paper is a three phase full bridge five levels diode clamped inverter and this topology is shown in Fig. 1. The voltage across the phase winding of the induction motor can attain one of the five levels $-2 \mathrm{Vdc},-\mathrm{Vdc}, 0,2 \mathrm{Vdc}$ or $\mathrm{Vdc}$, depending upon the switching states of the inverters [14].

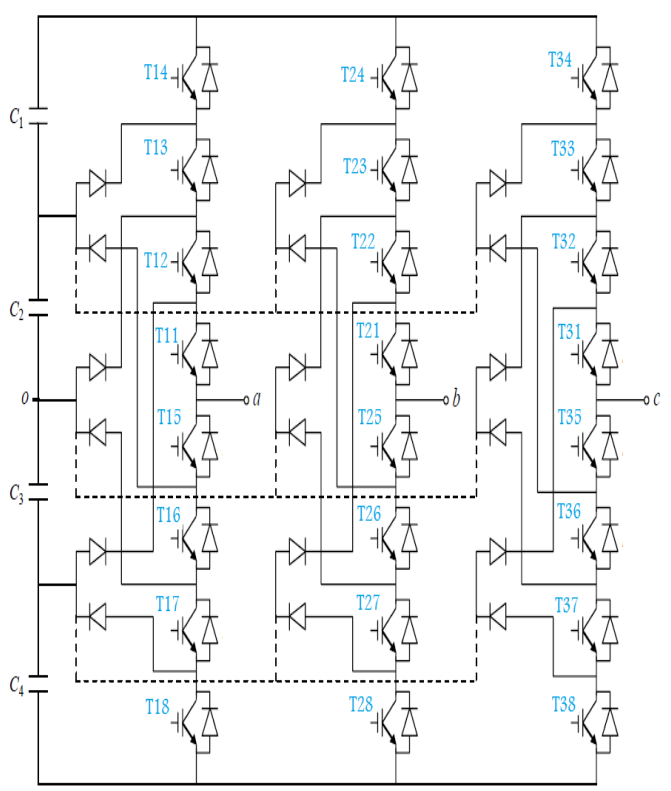

Fig. 1 Five-level diode clamped voltage source inverter

The five-level diode-clamped inverter leg has 4 DC link capacitors, 8 switches, five-levels output phase voltage and 9 levels output line voltage. Although each active switching device is required to block only a voltage level equal to the capacitor voltage of $\mathrm{Vc}=\mathrm{E} / 4$, the clamping diodes require different ratings for reverse voltage blocking. The necessary conditions for the switching states for the five-level inverter are that the dclink capacitors should not be shorted, and the output current should be continuous [15].

The representation of the space voltage vectors of a five-level inverter for all switching states is given by Fig. 2.

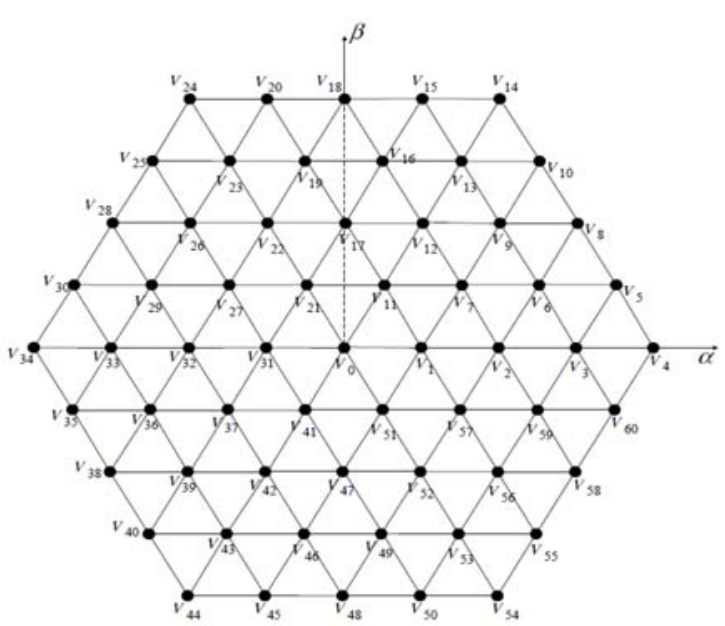

Fig. 2 Space vector diagram of five-level inverter.

\section{FIVE-LEVEL DIRECT TORQUE CONTROL}

Direct Torque and Flux Control (DTFC) is widely used for quick response and high efficiency control of induction motor drives [8]. The suggested control strategy is the Direct Torque Control (DTC) chosen for having a simpler structure compared to the Field Oriented Control strategy. Direct Torque Control is derived from the fact that, on the basis of the errors between the reference and the estimated values of torque and flux, it is possible to directly control the inverter states in order to reduce the torque and flux errors within the prefixed band limits [16].

The basic model of five-level DTC induction motor scheme is shown in Fig. 3. In the five-level DTC structure, it employs a pair of hysteresis comparator, one utilizes a two-level hysteresis comparator for controlling the flux and the other one uses a three-level hysteresis comparator for controlling the torque.

In this method measured terminal variables are utilized to estimate instantaneous value of the flux and torque. From the estimated value of flux and torque an optimal switching vector is selected to directly control the torque [4].

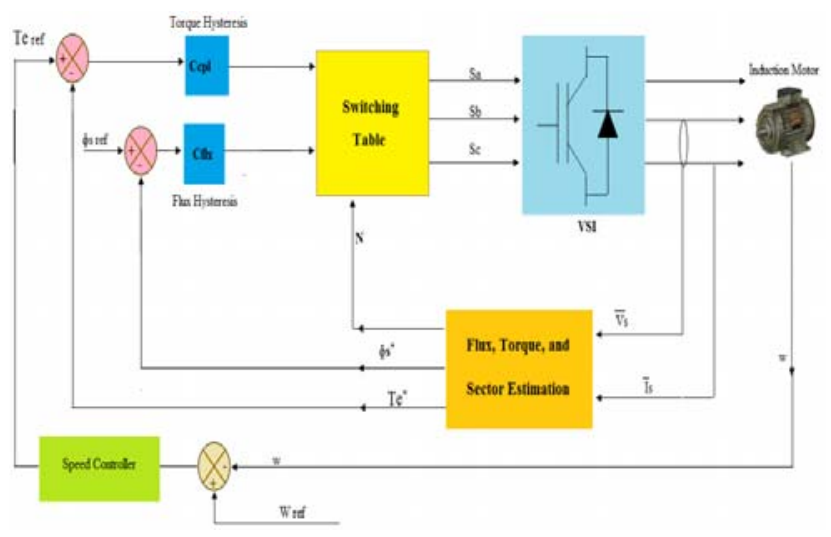

Fig. 3 Block diagram of DTC of IM drives.

The stator flux can be evaluated by integrating from the stator voltage equation [17]: 


$$
\Phi_{S}=\int_{0}^{t}\left(V_{S}-R_{S} \cdot i_{S}\right) d t
$$

The magnitude of the stator flux can be estimated by

$\Phi_{S}=\sqrt{\Phi_{s \alpha}^{2}+\Phi_{s \beta}^{2}}$

The stator flux sector is determined by the components $\Phi_{S \alpha}$ and $\Phi_{s \beta}$. The angle between the referential and $\Phi_{S}$ is equal to [18]:

$$
\theta=\operatorname{arctg}\left(\frac{\Phi_{\mathrm{s}} \beta}{\Phi_{\mathrm{s}} \alpha}\right)
$$

Torque can be calculated using the components of the estimated flux and measured currents:

$$
T e=\frac{3}{2} p\left(\Phi_{s \alpha} i_{S} \beta-\Phi_{S} \beta i_{s} \alpha\right)
$$

The switching selection block in Fig. 3 receives the input signals Ccpl, Cflx and $\mathrm{N}$ generate the desired control voltage vector as given in look-up table shown in Table 1.

Table 1 Switching Table of five-level inverter

\begin{tabular}{|c|c|c|c|c|c|c|}
\hline \multirow{2}{*}{ Sector } & \multicolumn{7}{|c|}{ Cf1x } \\
\cline { 2 - 7 } & \multicolumn{7}{|c|}{$\mathbf{1}$} & \multicolumn{4}{|c|}{ 0 } \\
\cline { 2 - 7 } $\mathbf{N}$ & $\mathbf{7}$ & $\mathbf{0}$ & $\mathbf{- 1}$ & $\mathbf{1}$ & $\mathbf{0}$ & $\mathbf{- 1}$ \\
\cline { 2 - 7 } & 14 & 2 & 54 & 24 & 32 & 44 \\
\hline $\mathbf{1}$ & 18 & 7 & 58 & 28 & 37 & 48 \\
\hline $\mathbf{2}$ & 24 & 12 & 4 & 34 & 42 & 54 \\
\hline $\mathbf{3}$ & 28 & 17 & 8 & 38 & 47 & 58 \\
\hline $\mathbf{4}$ & 28 & 14 & 44 & 52 & 4 \\
\hline $\mathbf{5}$ & 34 & 22 & 18 & 48 & 57 & 8 \\
\hline $\mathbf{6}$ & 38 & 27 & 18 & 54 & 2 & 14 \\
\hline $\mathbf{7}$ & 44 & 32 & 24 & 54 & 7 & 18 \\
\hline $\mathbf{8}$ & 48 & 37 & 28 & 58 & 7 & 24 \\
\hline $\mathbf{9}$ & 54 & 42 & 34 & 4 & 12 & 28 \\
\hline $\mathbf{1 0}$ & 58 & 47 & 38 & 8 & 17 & 28 \\
\hline $\mathbf{1 1}$ & 4 & 52 & 44 & 14 & 22 & 34 \\
\hline $\mathbf{1 2}$ & 8 & 57 & 48 & 18 & 27 & 38 \\
\hline
\end{tabular}

\section{DESIGN OF ANN TORQUE RIPPLE OPTIMIZATION}

In order to improve the five-level DTC performances a complimentary use of neural networks controller is proposed. ANN is part of the family of statistical learning methods inspired by biological nervous system and are used to estimate and approximate functions that depends only on a large number of inputs [19].

A group of artificial neurons, which work in parallel, their inputs and outputs have the same destination from a layer. Each neural network must contain at least one layer of neurons but can join as many as someone projects. The layer gathering the neurons which give the output of the neural networks is called output layer. Layers which contain the neurons interposed between the global inputs of the neural network and the inputs of the neurons from the output layer are called hidden layers. Usually, there are used feed-forward $\mathrm{NN}$ which contains a hidden layer and an output layer [20].

The principle of neural networks direct torque control (NNDTC) is similar to traditional DTC. The difference is using a neural networks controller to replace the torque hysteresis loop controller. As shown in Fig. 4.

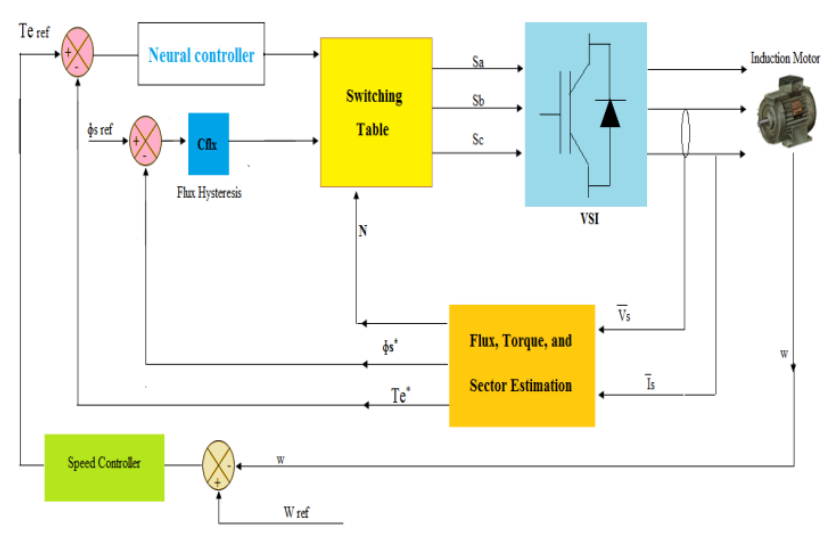

Fig. 4 Neural network DTC scheme

The block diagram for neural networks based torque hysteresis controller is shown in Fig. 5.

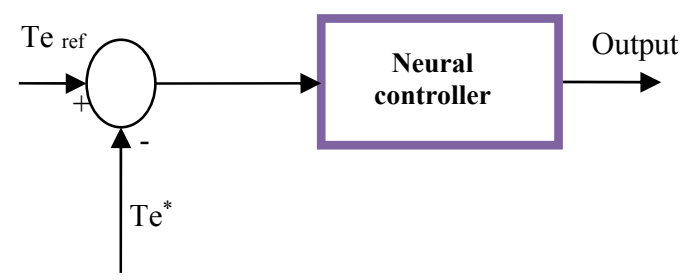

Fig. 5 Neural networks control of torque hysteresis controller.

The ANN has many models, but the usual model is the multilayer feed forward net work using the error back propagation algorithm [6]. Such a neural network contains three layers: input layers, hidden layers and output layers. Each layer is composed of several neurons. The number of the neurons in the input and output layers depends on the number of the selected input and output variables. The number of hidden layers and the number of neurons in each depending on the desired degree of accuracy [6].

The structure of the neural to perform the DTC applied to IM satisfactorily was a neural network with one linear input node, 4 neurons in the hidden layer, and one neuron in the output layer, as shown in Fig. 6.

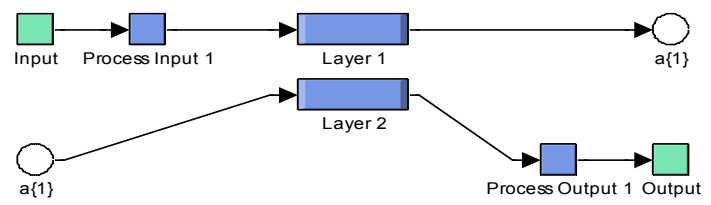

Fig. 6 Neural network structure for five-level DTC

The structure of Layer 1 is shown in Fig. 7, and the IW of Layer 1 is shown in Fig. 8. 
The Layer 2 of ANN as it is shown in Fig. 9. The structure of LW for Layer 2 is shown in Fig. 10.

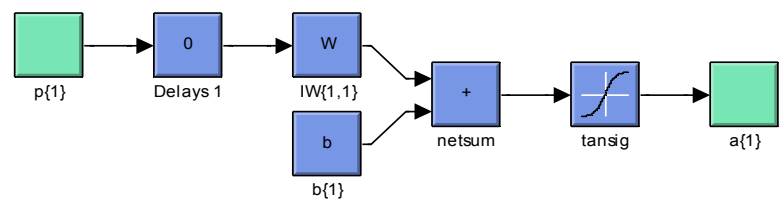

Fig. 7 Architecture of Layer 1

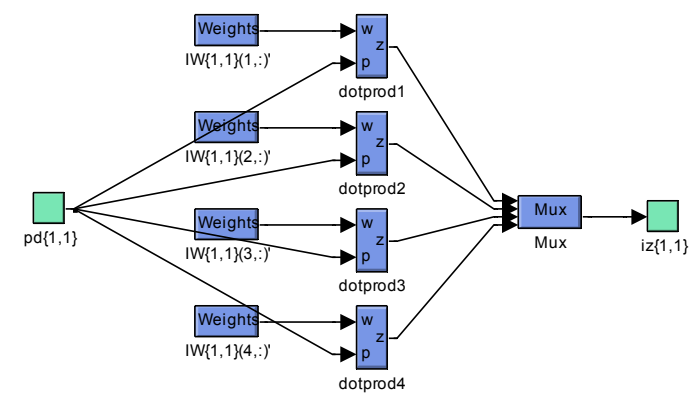

Fig. 8 Block diagram of IW for layer 1

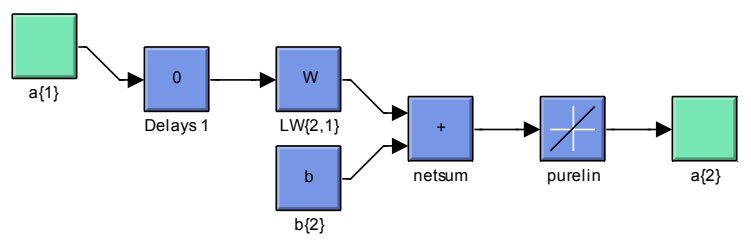

Fig. 9 Architecture of Layer 2

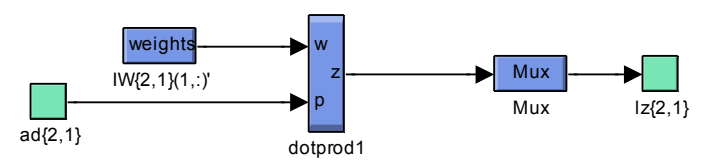

Fig. 10 Block diagram of LW for layer 2

\section{RESULTS}

The simulations of the five-level NNDTC induction motor drive are compared with five-level DTC classique. A 3-phase, 3 pole, induction motor with parameters of $\mathrm{Rs}=0.228 \Omega ; \quad \mathrm{Rr}=0.332 \Omega ; \quad \mathrm{Ls}=0.0084 \mathrm{H} ; \quad \mathrm{Lr}=0.0082 \mathrm{H}$; $\mathrm{Lm}=0.0078 \mathrm{H} ; \quad \mathrm{J}=20 \quad \mathrm{Kg} . \mathrm{m} 2$ are considered.The performance analysis is done with stator current, stator flux and torque plot. The dynamic performance of the five-level DTC control with induction motor is shown Fig. 11. The dynamic performance of the five-level DTC control with neural network controller is shown Fig. 12.

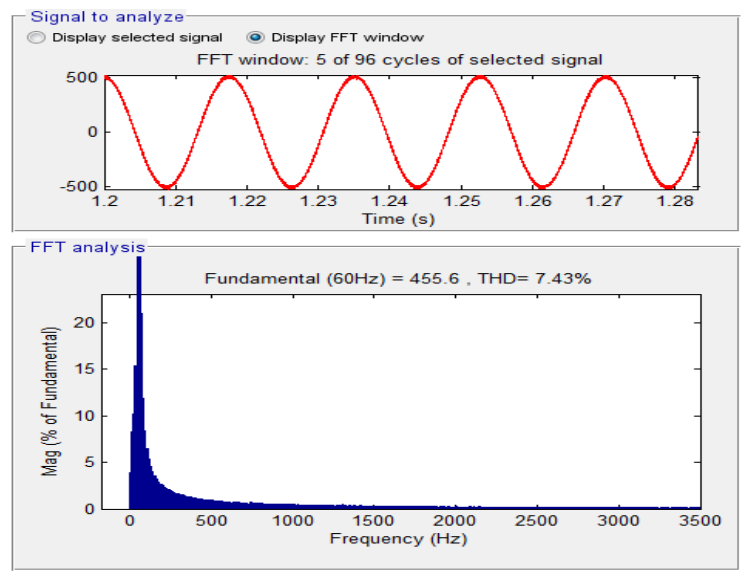

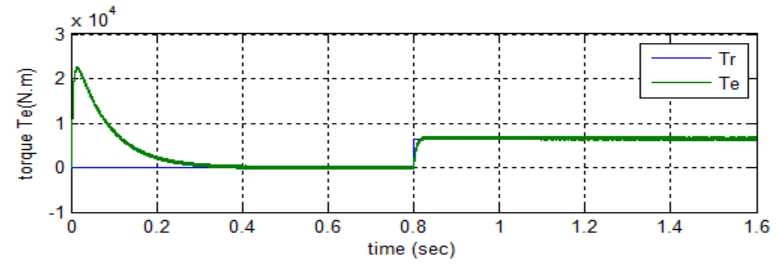
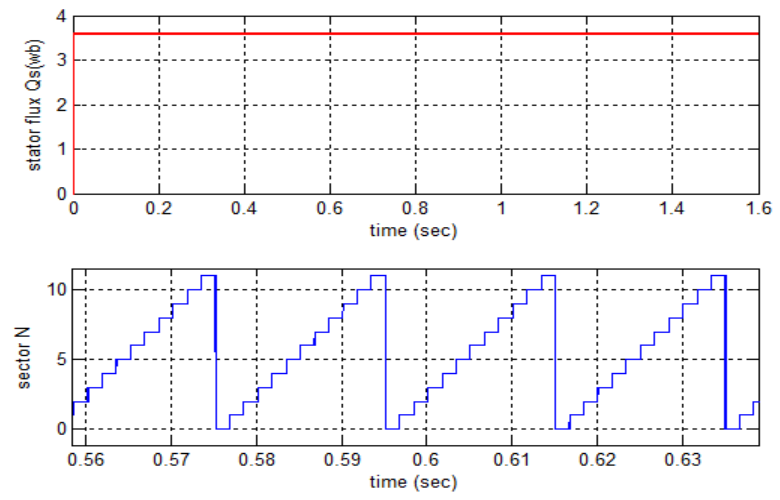

Fig. 11 Dynamic responses of five-level DTC for IM
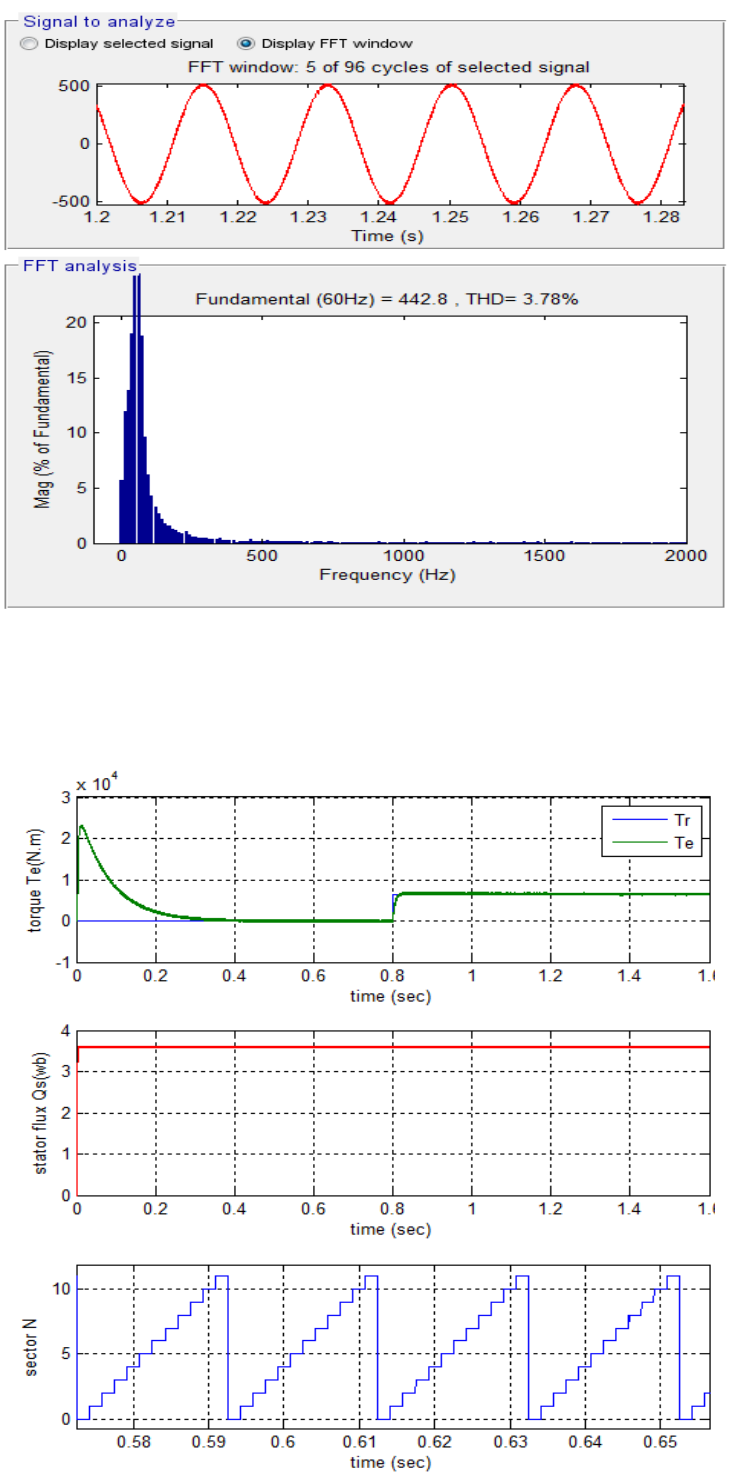

Fig. 12 Dynamic responses of neural five-level DTC for IM 
Fig. 13 shows the stator flux responses of both the conventional and neural five-level DTC schemes. It is found that the proposed variable band torque hysteresis controller based DTC scheme exhibits smooth response and lesser ripple in flux as compared to the conventional five-level DTC scheme.

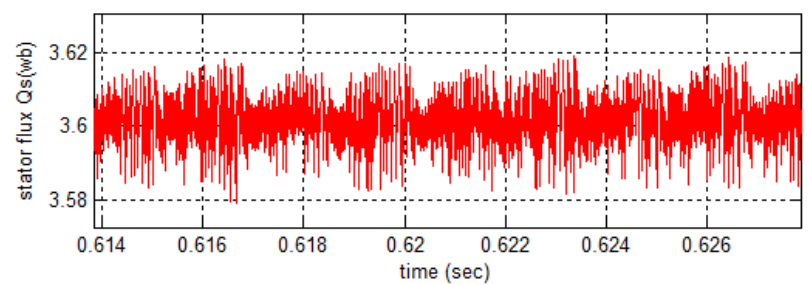

a) Five-level DTC

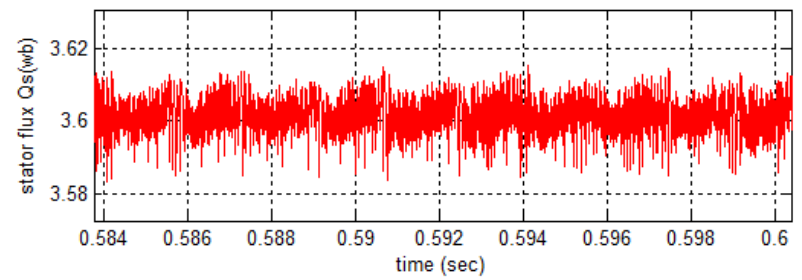

b) Neural five-level DTC

Fig. 13 Zoom of stator flux

Torque response comparing curves are shown in Fig. 14. See figure the torque ripple is significantly reduced when the neural controller is in use.

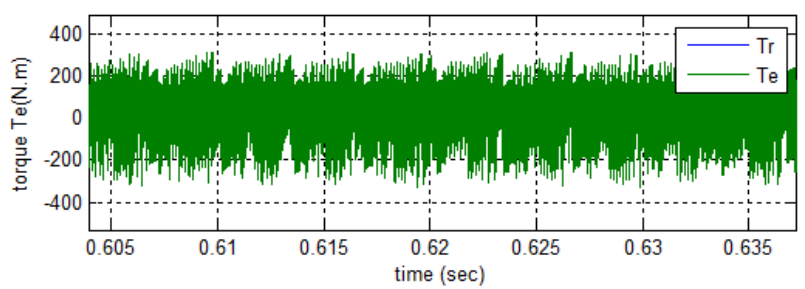

a) Five-level DTC

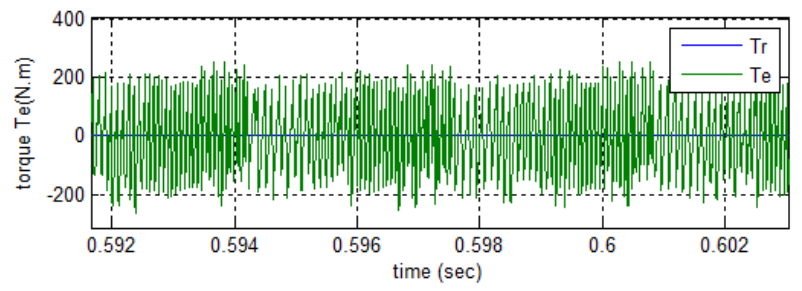

b) Neural five-level DTC

Fig. 14 Zoom of torque

In Table 2, I summarize the simulation results obtained by conventional five-level DTC and the proposed DTC control.

It can be concluded from Table 2 that strategy proposed of DTC control is more efficient than the conventional DTC command of the induction motor powered by five-level inverter.

Table 2 Comparison between the five-level DTC and the neural five-level DTC

\begin{tabular}{|c|c|c|}
\hline & Five-level DTC & Neural five-level DTC \\
\hline $\begin{array}{c}\text { Ias } \\
\text { THD } \\
(\%)\end{array}$ & 7.43 & $\mathbf{3 . 7 8}$ \\
\hline
\end{tabular}

The dynamics of the components of the stator flux are not affected by the application of these load guidelines.

\section{CONCLUSIONS}

This paper presents a five-level DTC for the induction motor with neural networks controller. This controller determinates the desired amplitude of torque hysteresis band. The proposed scheme was simulated and compared with conventional five-level DTC using Matlab/Simulink. The five-level DTC with neural controller decreases considerably the torque ripples and stator flux.

\section{REFERENCES}

[1] HASSAN ADEL, A. - ABO-ZAID, S. - REFKY, A.: Improvement of direct torque control of induction motor drives using neuro-fuzzy controller, Journal of Multidisciplinary Engineering Science and Technology (JMEST), Vol. 2, issue 10, 2015.

[2] FETHI AIMER, A. - BENDIABDELLAH, A. MILOUDI, A. - MOKHTARI, C.: Application of fuzzy logic for a ripple reduction strategy in DTC scheme of a PWM inverter fed induction motor drives, Journal of Electrical Systems, Special Issue, No. 1, pp. 13-17, 2009.

[3] AMEUR, A. - MOKARNI, L. - MOKHTARI, B. ESSOUNBOULI, N. - AZOUI, A.: Intelligent DTC of PMSM, fed by a three-phase NPC three-level inverter," Acta Electrotehnica, vol. 55, No. 1-2, 2014.

[4] DIDARUL ISLAM, MD. - REZA, C. M. F. S. MEKHILEF, S.: Medeling and experimental validation of 5-level hybrid H-bridge multilevel inverter fed DTC-IM drive," J. Elect. Eng. Technol, Vol. 10, No. 2, pp. 754-585, 2015.

[5] SUNDRAM, R. - BIN JIDIN, A. - SUTIKNO, T. LOGAN RAJ, L.: Improvise 3-level DTC of induction machine using constant switching frequency method by utilizing multiband carrier, International Journal of Power Electronics and Drive System (IJPEDS), Vol. 7, No. 3, pp. 638-647, Sep. 2016.

[6] BENYOUSSEF, E. - MEROUFEL, A. - BARKAT, S.: Three-level DTC based on Fuzzy logic and neural network of sensorless DSSM using extende kalman filtre, International Journal of Power Electronics and Drive System (IJPEDS), Vol. 5, No. 4, pp. 453-463, Apr. 2015.

[7] RAJASEKARAN, P.-JAWAHAR SENTHIKUMAR, V.: An improved DTFC based five levels-NPC inverter fed induction motor for torque ripple minimization, International Journal of Power Electronics and Drive System (IJPEDS), Vol. 7, No. 2, pp. 531-542, Jun. 2016.

[8] SUDHEER, H. - KADAD, SF. - SARVESH, B.: Direct torque and flux control of induction machine using fuzzy logic controller, Journal of Electrical Engineering, Vol. 17, No. 2, 2017. 
[9] A. ABBOU, A. - MAHMOUDI, H.: Performance of a sensorless speed control for induction motor using DTFC strategy and intelligent techniques, Journal of Electrical Systems, Vol. 3-5, No. 6, pp. 64-81, 2006.

[10] MOKHTARI, B. - BENKHORIS, M. F.: High ripples reduction in DTC of induction motor by using a new reduction switching table, Journal of Electrical Engineering, Vol. 67, No. 3, pp. 206-211, 2016.

[11]PAVANAJYOTHI, G. - BHAGYA LAKASHMI, M.: Implementation of new PWM method for diode clamped multilevel inverter, International Journal of Scientific Engineering and Applied Science, Vol. 1, issue 7, 2015.

[12] CHIBANI, R. - BERKOUK, E. M. - BOUCHERIT, M. S.: Five-level NPC-VSI capacitor voltage balancing using a novel clamping bridge, Asian Power Electronics Journal, Vol. 5, No. 1, 2011.

[13] MANIVARMA, M. - SUYUNA, J. - VIMAL RAJ, P.: Comparison of saven level inverter with reduced number of switches and their Thd's in PI controller, Journal of Electronics and Communication Engineering, pp. 32-42, 2016.

[14] LAXMINARAYANA, G. - PRADEEP, K.: Comparative analysis of 3-, 5- and 7-level inverter using space vector PWM, International of Advanced Research in Electrical, Electronics and Instrumentation Engineering, Vol. 2, issue 7, 2013.

[15]ABDELKRIM, T. - BENAMRANE, K. BENKHELIFA, AEH. - E. M. BERKOUK, E. M. BENSLIMANE, T.: Five-level diode clamped active power filtre for high power utilities, International Journal of Science and Techniques of Automatic Control \& Computer Engineering, Vol. 5, No. 2, pp. 1634-1647, 2011.
[16]BEN ALAYA, J. - KHEDHER, A. - FAOUZI MIMOUNI, M.: Speed-Sensorless DFIG wind drive based on DTC using sliding mode rotor flux observer, International Journal of Renewable Energy Research, Vol. 2, No. 4, 2012.

[17] MEROUFEL,A. - MASSOUM,S. - BENTAALLAH, A. - WIRA, P.: Double star induction motor direct torque control with fuzzy sliding mode speed controller, Rev. Roum. Sci. Techn.-Electrotechn. Et Energ, Vol. 62, No. 1, pp. 31-35, 2017.

[18] A. IDIR, A. - KIDOUCHE, M.: Direct torque control of three phase induction motor drive using fuzzy logic controllers for low torque ripple, Proceedings Engineering \& Technology, Vol. 2, pp. 78-83, 2013.

[19] NARASIMHA RAO, D. - SURENDRA, T. - TARA KALYANI, S.: DPFC performance with the comparison of PI and ANN controller, International Journal of Electrical and Computer Engineering (IJECE), Vol. 6, No. 5, pp. 2080-2087, Oct. 2016.

[20] MICU, D. D. - CZUMBIL, L. - CHRISTOFORIDIS, G. - SIMION, E.: Neural networks applied in electromagnetic interference problems, Rev. Roum. Sci. Techn.-Electrotechn. Et Energ, Vol. 57, No. 2, pp. 162-171, 2012.

Received August 27, 2017, accepted November 15, 2017

\section{BIOGRAPHY}

Habib Benbouhenni was born in chlef, Algeria. He is a PhD student in the Departement of electrical engineering at the ENPO-MA, Oran, Algeria. He received a M.S. degree in Automatic and informatics industrial in 2017. His research activities include the application of robust command in the wind turbine power systems. 